\title{
Actualidad extranjera
}

\author{
AnÍBAL ZÁrATE ${ }^{1}$
}

Si el derecho administrativo históricamente se funda en su caracterización como régimen jurídico distinto del régimen de derecho común u ordinario ${ }^{2}$, cuestionarse acerca de su legitimidad supone desconocer la necesidad de distinguir entre dichos regímenes. Es en estos términos que la reciente obra del profesor Philip Hamburger, Is Administrative Law Unlawful? ${ }^{3}$ reanima una discusión que, a partir de la comparación con la idea francesa de una desigualdad entre sujetos públicos y privados frente a la ley ${ }^{4}$, pretende ver el derecho administrativo como algo extraño a la tradición de los países de la Common Law.

1 Doctor en Derecho de la Universidad Panthéon-Assas, Paris II, Paris, Francia. Docenteinvestigador y director del Grupo de Investigación del Departamento de Derecho Administrativo de la Universidad Externado de Colombia, Bogotá, Colombia. Correo-e: anibal.zarate@uexternado.edu.co Para citar el artículo: Zárate, A. "Actualidad extranjera", Revista digital de Derecho Administrativo, n. ${ }^{\circ} 16$, segundo semestre, Universidad Externado de Colombia, 2016, pp. 17-25. DOI: http://dx.doi.org/10.18601/21452946.n16.03.

2 Alberto Montaña, Fundamentos de derecho administrativo, Bogotá: Universidad Externado de Colombia, 2010, p. 29.

3 Philip Hamburger, Is Administrative Law Unlawful?, Chicago: The University of Chicago Press, 2014, 648 p. Esta obra no sólo ha sido el objeto de reseñas (GARY LAWSON, "The Return of the King: The Unsavory Origins of Administrative Law", Texas Law Review, 93, Book Review, 2015, p. 1521; Adrian Vermule, "Book Review", Texas Law Journal, 93, 2015, p. 1547), de citaciones y discusiones en artículos de doctrina (v. p. ej., CHRISTIAN BURSET, "Merchant Courts, Arbitration, and the Politics of Commercial Litigation in the Eighteenth-Century British Empire", Law and History Review, 34, 2016, p. 615; Jesús FernándeZ-VILLAVERDE, "Magna Carta, the Rule of Law and the Limits on Government", International Review on Law and Economics, 47, 2016, p. 22, CALEB NelSON, "The Constitutionality of Civil Forfeiture", Yale Law Journal, 125, p. 2446; Jon D. MiCHAELS, "Of Constitutional Custodians and Regulatory Rivals: An Account of the Old and New Separation of Powers", New York University Law Review, 91, 2016, p. 227; ANDREw COAN, NiCHOlas Bullard, "Judicial Capacity and Executive Power", Virginia Law Review, 102, 2016, p. 765), sino que además ha sido referenciada en fallos jurisprudenciales (vid. United States v. Nichols, 2015, 784 F.3d, 665; Gutierrez-Brizuela v. Lynch, 2016, Tenth Circuit, WL 4436309 "Perhaps allowing agencies rather than courts to declare the law's meaning bears some advantages, but it also bears its costs. And the founders were wary of those costs, knowing that, when unchecked by independent courts exercising the job of declaring the law's meaning, executives throughout bistory had sought to exploit ambiguous laws as license for their own prerogative. See, e.g., Philip Hamburger, Is Administrative Law Unlawful? 287-91 (2014)").

4 Son conocidas las posiciones de autores como ALBERT DiCEY, para quien "the absence from our language of any satisfactory equivalent for the expression droit administratif is significant, the want of a name arises at bottom from our non-recognition of the thing itself."; vid. Introduction to the Study of the

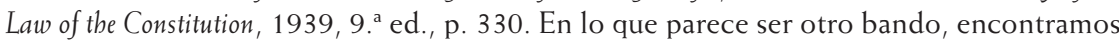


Revelando los antecedentes ingleses del derecho administrativo moderno estadounidense, el autor intenta mostrar que este no es más que la expresión contemporánea de una tendencia a la concentración del poder más allá y por fuera de la ley ${ }^{5}$. Este derecho no sería por consiguiente otra cosa distinta a una forma moderna de absolutismo continental; una traición al rule of Law de corte anglo-estadounidense y al concepto de libertad arraigado en la mente de los juristas ingleses de los siglos XVI y XVII. En Inglaterra, la prerrogativa del rey, comenta, era aquella ordinaria con la que se denominaban varias atribuciones reales reconocidas por la Common Law, y no una "extraordinaria", por fuera del derecho ${ }^{6}$, como dice que sucedía en el continente ${ }^{7}$. Pero, ¿cómo se manifiestan estas prerrogativas extraordinarias en el Administrative State? ${ }^{8}$. Bajo el sistema de derecho administrativo creado desde la era del progreso ${ }^{9}$, el autor sostiene que las agencias estadounidenses expiden tanto reglas generales de obligatorio cumplimiento, ejerciendo una competencia constitucionalmente atribuida al legislador federa ${ }^{10}$, como órdenes vinculantes cuya competencia es de los jueces ${ }^{11}$. Lo que se traduce en un desconocimiento del principio de la separación de poderes, situación que se acentúa a causa de la "deferencia"

las opiniones de juristas como CECIL THOMAS CARR, quien encuentra que "this negative liberty view of the project of administrative law ignores the positive functions of the state and the role of law in shaping effective administration"; vid. Concerning English Administrative Law, 1941, p. 22-23.

5 El derecho administrativo representaría entonces las formas de acción gubernamental que el constitucionalismo estadounidense buscaba precisamente prevenir.

6 HAmburger equipara la actividad "extralegal" de las agencias a las prerrogativas imperiales en la antigua Roma, bajo la cual el emperador llenaba los vacíos en la ley; vid. PHILIP HAMBURGER, ob. cit., p. 54.

7 Citando la obra de ALBERT DiCEY sobre el droit administratif, HAMBURGUER traza los orígenes del derecho administrativo hasta los sistemas francés y alemán, y hasta el Ordnung o administración burocrática del antiguo régimen prusiano, por lo que el derecho administrativo representaría la "prusificación" de la sociedad estadounidense; idid. ob. cit., pp. 447, 505.

8 La literatura sobre el Administrative State es abundante. Vid., entre la bibliografía que existe sobre el tema, Michael E. PARRish, "The Great Depression, the New Deal and the American Legal Order", Washington Law Review, 59, 1984, p. 723; T. LOWI, The End of Libaralism, Ideology, Policy, and the Crisis of Public Authority, New York: Norton \& Co., 1969; EDWARD RuBIN, "Getting Past Democracy", University of Pennsylvania Law Review, 149, 2001, p. 711; y más reciente Jeremy K. Kessler, "The Political Economy of "Constitutional Political Economy", Texas Law Review, 94, 2016, p. 1527; Catherine M. SharkeY, "The Administrative State and the Common Law: Regulatory Substitutes or Complements?", Emory Law Journal, 65, 2016, p. 1705.

9 Sobre la era del progreso vid. StePhen SkOwreneK, Building a New American State: The Expansion of National Administrative Capacities: 1877-1920, Cambridge: Cambridge University Press, 1982. Para un estudio completo de la historia de las agencias estadounidenses, vid. Robert L. Rabin, "Federal Regulation in Historical Perspective", Standford Law Review, 38, 1986, p. 1189.

10 Hamburger, ob. cit., p. 32.

11 Ibíd., p. 129. 
que los jueces tienen con la Administración ${ }^{12}$. Son estas mismas revelaciones las que meritan aquí ser indagadas.

Situar los orígenes del derecho administrativo estadounidense en la era del progreso es en primer lugar disputado. Para el profesor Jerry MASHAW, la concepción según la cual el derecho administrativo aparece en Estados Unidos, en 1887, con la creación de la Comisión del comercio interestatal ${ }^{13}$, se edifica sobre dos mitos que están relacionados entre si $^{14}{ }^{14}$. La afirmación de que el gobierno federal desde 1787 hasta bien entrada la segunda mitad del siglo XIX era de cortes y partidos ${ }^{15}$, en el que los remedios judiciales tomaban sea la forma de una acción de la Common Law contra el oficial que actuaba, sea la forma de una disputa sobre la constitucionalidad de la ley que autorizaba a dicho funcionario, reproduce la creencia errónea de que el derecho administrativo es exclusivamente el derecho del control judicial de los actos de la administración (judicial review) ${ }^{16}$. Con relación al primero de los mitos, el autor señala que, desde los comienzos de la República, el Congreso federal delegó amplia autoridad a administradores, quienes, armados de poderes coercitivos extrajudiciales, crearon todo un sistema de adjudicación administrativa. De hecho, la primera agencia independiente a nivel nacional sería la Oficina de

12 Ibíd., p. 280, 316. El caso emblemático en este tema es la jurisprudencia Chevron de 1984 (104 S.Ct. 2778), aunque es pertinente consultar también U.S. v. Mead Corp., 121 S.Ct. 216499 (2001), Massachusetts v. EPA 127 S.Ct. 1438, (2007), 549 U.S. (2007), National Association of Home Builders v. Defenders of Wildlife 127 S. Ct. 2518 (2007), 551 U.S. (2007). Sobre el concepto de deferencia en el derecho administrativo federal estadounidense, vid. Connor N. Raso, William N. Eskridge, Jr., "Chevron as a Canon not a Precedent: An Empirical Study of What Motivates Justices in Agency Deference Cases", Columbia Law Review, 110, 2010, p. 1727; Timothy K. Armstrong, "Chevron Deference and Agency Self-Interest", Cornell Journal of Law \& Public Policy, 13, 204, p. 203. En francés, DominIQUE Custos, "La jurisprudence administrative de la Cour Suprême américaine d'octobre 2006 á juin 2007", Droit administratif, 1, janvier 2008, Crhon. 1, p. 1.

13 Interstate Commerce Commission (ICC); sobre los orígenes de la ICC, vid. ARI HOOGENBOOM, Olive Hoogenboom, A History of the ICC: From Panacea to Palliative, New York: Norton, W. W. \& Company, 1976, p. 32.

14 Jerry L. MASHAW, "Recovering American Administrative Law: Federalist Foundations, 1787-1801", Yale Law Journal, 115, 2006, p. 1256.

15 A pesar de que el autor no cuestiona la principal reivindicación que hace STEPHEN SKOWRONEK de que las cortes y los partidos eran elementos centrales en la estructura del gobierno de Estados Unidos en el antebellum, sí cuestiona la noción implícita en la obra de SKOWRONEK acerca de que "the administrative institutions created in the Federalist period (and maintained with little significant change until Andrew Jackson's presidency) and the means by which they were made accountable by law were minor aspects of governance, of little significant for our understanding of the structure of the infant Republic": JERRY L. MASHAW, ob. cit., nota 3.

16 Pero esta visión nunca fue unánime. Para CARR, Albert DiceY estaba equivocado: "He wasted pity on the French for being at the mercy of officials whom they could not bring into the ordinary courts, when in trutb the special courts for deciding disputes between citizens and officials in France were working most acceptably and giving a practical remedy where English citizens got none" (CARR, citado por JERRY L. MASHAW, ob. cit., p. 1260). 
Patentes, establecida noventa y cinco años antes que la ICC ${ }^{17}$. Con relación al segundo de los mitos, Mashaw advierte que la responsabilidad (accountability) de la Administración difícilmente termina en las cortes, de modo que los agentes del gobierno son igualmente responsables ante las ramas ejecutiva y legislativa. "Los oficios de la administración reciben sus poderes, recursos humanos y financieros, su estructura interna y los procedimientos que deben seguir, no de las cortes que revisan su actuación, sino del Congreso y de los presidentes que las crean, les asignan funciones y monitorean su actividad"18. Es el desconocimiento de estos controles por parte de las ramas tradicionales del poder público un punto central en la tesis de Hamburger.

La ilegalidad del derecho administrativo estadounidense yacería, en segundo lugar, en el aparente ejercicio extralegal de funciones normativas por parte de autoridades administrativas. Esta afirmación del profesor Hamburger es más difícil de sostener, puesto que, si las agencias cumplen estas funciones, ellas lo hacen bajo la autoridad del Congreso. Con esto no se quiere indicar que las agencias no puedan actuar de manera arbitraria en el ejercicio de los poderes delegados ${ }^{19}$, pero esto no es un problema de todo el Estado administrativo, ni un elemento que permita cuestionar por entero su legitimidad. La crítica a la delegación de funciones normativas a las agencias no es tampoco exclusiva a Hamburger. De hecho, autores como David Schoenbrod señalan que las delegaciones legislativas son incompatibles con la democracia, toda vez que ellas socavan el poder más grande que tienen los ciudadanos, consistente en no volver a elegir a quienes expidan malas leyes ${ }^{20}$. Estas posturas parecen desconocer la jurisprudencia de la Corte Suprema que niega que haya una delegación hasta tanto el Congreso no establezca un "principio ininteligible" para guiar el ejercicio de la función delegada ${ }^{21}$. Cuando existe dicho principio, la autoridad

18 "The task of administrative law is to generate institutional designs that appropriately balance the simultaneous demands of political responsiveness, efficient administration, and respect for legal rigbts": íbid., p. 1261.

19 Como parece demostrarlo la reciente jurisprudencia United States v. Texas de 2016, cuya pregunta principal consistió en saber si el gobierno de Estados Unidos había violado las normas de la ley de procedimiento administrativo (APA) y, en concreto, el deber de notificación y tratamiento de los comentarios del público en la expedición de rules.

20 A través de este mecanismo escaparía el Congreso de toda responsabilidad; vid. al respecto, David Schoendrod, Power without Responsability, How Congress Abuses the People Through Delegation, New Heaven, London: Yale University Press, 1993, p. 14; vid., además, M. Hamilton, "Representation and Nondelegation: Back to Basis", Cardozo Law Review, 20, 1999, p. 807.

21 En el derecho federal estadounidense, la facultad constitucionalmente reconocida al Congreso para crear una agencia es también un medio de este para controlarla. Al menos así lo ha entendido la Corte Suprema desde 1928, fecha en la que, incapaz de frenar una evolución que conduciría al paso del Estado liberal al Estado de bienestar, ella establece una regla según la cual toda delegación legislativa debe enunciar unos estándares para guiar y encuadrar el ejercicio de la función delegada a las agencias. Vid. J.W. Hampton, 
administrativa delegataria ejerce un poder ejecutivo, tal como lo recuerda la jurisprudencia City of Arlington, al indicar que las agencias establecen reglas y realizan actividad de adjudicación desde los comienzos de la República. "Si bien estas actividades toman la forma de una función 'legislativa' o 'judicial', ellas son el ejercicio de una función de carácter ejecutivo"22.

Es precisamente la atribución de funciones denominadas cuasi-jurisdiccionales y cuasi-normativas lo que conduce a Hamburger a afirmar que el derecho administrativo estadounidense es abiertamente contrario al principio de la separación de poderes contenido en la Constitución de ese país. Encontramos dos flaquezas en esta postura. Ella desconoce, de un lado, el hecho de que las agencias detentan estas funciones únicamente cuando hay una decisión de por medio, contenida en una ley que expide el Congreso, el Presidente sanciona $\mathrm{y}$ los jueces sostienen frente a cualquier reproche de inconstitucionalidad ${ }^{23}$. Por otro lado, el autor asume que el derecho administrativo autoriza a las agencias a ejercer "poderes combinados", siendo que lo que hace el derecho administrativo es, en algunos supuestos y bajo ciertos procedimientos específicos, consentir y enmarcar el ejercicio de esos "poderes combinados" 24 La expresión tal vez más evidente de la existencia de reglas especiales para encuadrar el ejercicio de estas diferentes actividades la constituye en efecto el Administrative Procedure Act (APA) de 1946, cuyas disposiciones exigen por ejemplo una estricta separación entre las funciones de adjudicación y aquellas de investigación y acusación ${ }^{25}$; o el cumplimiento de ciertas exigencias como la notificación y recepción de comentarios del público para la elaboración de reglas (rulemaking) ${ }^{26}$.

La ley de procedimiento administrativo ${ }^{27}$ se muestra por lo demás como una especie de compromiso entre las diferentes ramas del poder público del

Jr. \& Co.v. United States, 276 us 394, 409 (1928). "The 'intelligible principle' doctrine steers between these perils, attempting to sort executive power to 'fill in the details' from legislative power to set the overall direction for policy": ADRIAN VERMULE, ob. cit., p. 1554.

22 "Agencies make rules ('Private cattle may be grazed on public lands $X, Y$, and $Z$ subject to certain conditions') and condcut adjudications ('This rancher's grazing permit is revoked for violation of the conditions') and have done so since the begining of the Republic. These activities take 'legislative' and 'judicial' forms, but they are exercises of - indeed under our constitutional structure they must be exercises of - the executive power": 133 S. Ct., 1873 nota 4.

23 Para Vermule, se desconocen varios fallos como Chenery II (332 U.S. 194, 1947); FTC $v$. Cement Institute (333, U.S. 683, 1948), Wong Yang Sung (339 U.S., 33, 1950); Marcello v. Bonds (349 U.S., 302 1955); Withorw v. Larkin (421 U.S. 35, 1975): vid. Adrian Vermule, ob. cit., p. 1557.

24 Ibíd., p. 1558

25 Ibíd., p. 1557.

265 USCA, secc. 553(c). Como lo ilustra el reciente caso United States v. Texas; vid. supra nota 19; vid., además, ANNE Joseph O'Connell, "Political Cycles of Rulemaking: An Empirical Portrait of the Modern Administrative State", Virginia Law Review, 94, 2008, p. 889.

En 1946 el Congreso federal adopta una ley sobre procedimiento contencioso y no con- 
orden federal estadounidense, tendiente a superar las críticas formuladas al Estado administrativo. La evolución que comporta la política del New Deal es la manifestación de una filosofía intervencionista conforme a la cual al Estado le corresponde actuar, a través de agencias, con el fin de identificar problemas económicos y sociales y resolverlos directamente, en lugar de dejarlos a la solución del libre juego del mercado y de los intereses privados. Por más tentadora que esta fórmula parezca, las avalanchas de críticas al armazón administrativo puesto en marcha para realizar este intervencionismo no se hicieron esperar. De ahí que el término Administrative State sea empleado por algunos con consternación, y por otros incluso con reprobación ${ }^{28}$.

Si la visión de Hamburger según la cual existe un orden constitucional anglo-estadounidense, producto de los principios revelados por los jueces de la Common $\mathrm{Law}^{29}$, al que resultaría contraria toda discriminación entre sujetos públicos y privados en su sujeción a la ley, puede ser coherente con un momento histórico, lo cierto es que esta consideración teórica debe contextualizarse ${ }^{30}$. Lo que ha sido el desarrollo histórico del derecho administrativo conduciría a que este no solo hiciese suya la protección de los derechos individuales ${ }^{31}$, sino que además adoptara la realización del bienestar común o social como $\operatorname{tarea}^{32} \mathrm{y}$, más recientemente, la búsqueda de una legitimidad en y por sus actuaciones $^{33}$. Pero, cestá completo este desarrollo histórico? Claro que no.

tencioso de las agencias federales en sus relaciones con los administrados, y hasta hoy día constituye uno de los pilares centrales del derecho administrativo estadounidense.

Vid. supra nota $8 ;$ y agréguese JOHN A. RHOR, How to run a Constitution: The Legitimacy of the Administrative State, Lawrence: University Press of Kansas, 1986, p. 55. U otro reciente trabajo del mismo HamburGer, de septiembre de este año, "Chevron Bias", George Washington Law Review, 84, 2016, p. 1187.

GaRY LaWSON, ob. cit., p. 1523.

30 Alberto MONTAÑA, ob. cit., p. 30.

31 Jean-Bernard Auby, "Droit administratif et démocratie", en Régulation économique et démocratie, Martine Lombard (dir.), Paris: Dalloz, 2006, p. 13.

32 Un contemporáneo de DiCEY, el profesor estadounidense GOODNOW, ya incluía en su obra sobre los principios del derecho administrativo de Estados Unidos, como interés del derecho administrativo, el bienestar social. "The third interest to be regarded by the administrative law is the social well-being. There must be some method of control devised which will force the administration in its action to keep before it always the fact that it is not a law unto itself; that one of the great reasons of its existence is the promotion of the social well-being as expressed in the law. Sucb method of control should be organized as to allow that a body which is most thoroughly representative of public opinion - that is, the legislature- to step in and compel the administration to obey the law": FRANK GOODNOW, The Principles of the Administrative Law of the United States, 1905, pp. 371, 372.

33 JeAn-Bernard Auby, ob. cit., p. 16: "Au demeurant, c'est dans d'autres registres, de façon tout à fait consciente que notre droit administratif s'est éloigné de la vision selon laquelle son contenu démocratique lui viendrait du seul schéma représentatif. C'est même persuadé des limites de ces schémas que, comme on l'a rappelé, il s'est engagé, dans les années 1970, dans des réformes d'amélioration des rapports entre l'administration et les administrés, dans un processus de recherche de la 'démocratie administrative', dans la recherche d'une meilleure citoyenneté administrative". 
Trabajos como los del profesor Hamburger, más que llevarnos a tomar partido por la negación o no del derecho administrativo, deben conducirnos a una mejor comprensión de lo que tenemos, a un diálogo más robusto sobre las mutaciones y los retos que confronta nuestro Modern Administrative State.

\section{BIBLIOGRAFÍA}

Armstrong, Timothy K. "Chevron Deference and Agency Self-Interest", Cornell Journal of Law \& Public Policy, 13, 204, p. 203.

Auby, Jean-Bernard. "Droit administratif et démocratie", en Régulation économique et démocratie, MARTine LOMbaRd (dir.), Paris: Dalloz, 2006.

Burset, Christian. "Merchant Courts, Arbitration, and the Politics of Commercial Litigation in the Eighteenth-Century British Empire", Law and History Review, 34, 2016, p. 615.

Carr, Cecil Thomas. Concerning English Administrative Law, 1941.

Coan, Andrew, Bullard Nicholas. "Judicial Capacity and Executive Power", Virginia Law Review, 102, 2016, p. 765.

Custos, DominiQue. "La jurisprudence administrative de la Cour Suprême américaine d'octobre 2006 á juin 2007", Droit administratif, 1, janvier 2008, Crhon. 1, p. 1.

DiCEY, ALberT. Introduction to the Study of the Law of the Constitution, 9. a ed., 1939.

Fernández-Villaverde, Jesús. "Magna Carta, the Rule of Law and the Limits on Government", International Review on Law and Economics, 47, 2016, p. 22.

Goodnow, Frank. The Principles of the Administrative Law of the United States, 1905.

Hamburger, Philip. Is Administrative Law Unlawful?, Chicago: The University of Chicago Press, 2014, 648 p.

HamburGer, PhiliP. "Chevron Bias", George Washington Law Review, 84, 2016, p. 1187.

Hamilton, M. "Representation and Nondelegation: Back to Basis", Cardozo Law Review, 20, 1999, p. 807.

Hoogenboom, Ari y Hoogenboom, Olive, A History of the ICC: From Panacea to Palliative, New York: Norton, W. W. \& Company, 1976. 
Kessler, Jeremy K. "The Political Economy of 'Constitutional Political Economy'", Texas Law Review, 94, 2016, p. 1527.

LowI, T. The End of Libaralism, Ideology, Policy, and the Crisis of Public Authority, New York: Norton \& Co., 1969.

LaWsOn, Gary. "The Return of the King: The Unsavory Origins of Administrative Law", Texas Law Review, 93, Book Review, 2015, p. 1521.

MASHAW, JeRry L. "Recovering American Administrative Law: Federalist Foundations, 1787-1801", Yale Law Journal, 115, 2006, p. 1256.

Michaels, Jon D. "Of Constitutional Custodians and Regulatory Rivals: An Account of the Old and New Separation of Powers", New York University Law Review, 91, 2016, p. 227.

Montaña, Alberto. Fundamentos de derecho administrativo, Bogotá: Universidad Externado de Colombia, 2010.

Nelson, Caleb. "The Constitutionality of Civil Forfeiture", Yale Law Journal, 125, p. 2446.

O'Connell, Anne Joseph. "Political Cycles of Rulemaking: An Empirical Portrait of the Modern Administrative State", Virginia Law Review, 94, 2008, p. 889.

PARrish, Michael E. "The Great Depression, the New Deal and the American Legal Order", Washington Law Review, 59, 1984, p. 723.

Rabin, Robert L. "Federal Regulation in Historical Perspective", Standford Law Review, 38, 1986, p. 1189.

Raso, Connor N., ESKridge, William N. Jr., "Chevron as a Canon not a Precedent: An Empirical Study of What Motivates Justices in Agency Deference Cases", Columbia Law Review, 110, 2010, p. 1727.

RHOR, JOHN A. How to run a Constitution: The Legitimacy of the Administrative State, Lawrence: University Press of Kansas, 1986.

Rubin, Edward. "Getting Past Democracy", University of Pennsylvania Law Review, 149, 2001, p. 711.

Sharkey, Catherine M. "The Administrative State and the Common Law: Regulatory Substitutes or Complements?", Emory Law Journal, 65, 2016, p. 1705. 
Schoenbrod, David. Power without Responsability, How Congress Abuses the People Through Delegation, New Heaven, London: Yale University Press, 1993.

SkOwReneK, Stephen. Building a New American State: The Expansion of National Administrative Capacities: 1877-1920, Cambridge: Cambridge University Press, 1982.

Vermule, Adrian. "Book Review", Texas Law Journal, 93, 2015, p. 1547. 